\title{
An Unusual Case of Pain Abdomen
}

\author{
Wg Cdr AVS Anil Kumar*, Maj Sunitha BS ${ }^{+}$, Gp Capt RC Panda, vsm", Gp Capt AK Pujahari**, \\ Col PG Kumar ${ }^{++}$, Wg Cdr S Sampath"\#
}

MJAFI 2010; $66: 172-174$

Key Words : Pain abdomen; Lead poisoning; Basophilic stippling; Ayurvedic medication; Anaemia

\section{Introduction}

$\mathrm{T}$ he correct interpretation and diagnosis of pain abdomen is one of the most challenging demands made on a physician. One of the metabolic causes presenting as pain abdomen is lead poisoning [1]. Many a times the condition is overlooked and patient may have to undergo an unnecessary laparotomy [2]. This case highlights one such patient who initially presented with pain abdomen and was to be taken up for cholecystectomy.

\section{Case Report}

A 35 year old serving officer presented with complaints of upper abdominal colicky pain of four months duration which had aggravated three days prior to admission. There were no other complaints. He was a known case of cholelithiasis for which he was under surgical follow-up and psoriasis for which he was on Ayurvedic medication for the past six months with excellent response. On examination the vital parameters were normal. There were multiple healed psoriatic plaques over abdomen and lower limbs. Examination of abdomen and other systems did not reveal any abnormality. Ultrasonography (USG) abdomen revealed chronic calculus cholecystitis. Hence he was planned for elective cholecystectomy.

The routine preoperative evaluation revealed haemoglobin (Hb)-9.7g/dl, total leucocyte count (TLC)-6,000/cumm (65\% polymorphs, 35\% lymphocytes), platelets-1.8 lakh/cumm, bilirubin- $2.3 \mathrm{~g} / \mathrm{dl}$ (predominantly indirect), aspartate aminotransferase (AST)-146 IU/L, alanine aminotransferase (ALT)-180 IU/L, alkaline phosphatase-195 IU/L and normal routine urine examination. Peripheral blood smear (PBS) revealed normocytic normochromic anaemia with increased polychromasia. The reticulocyte count was $3 \%$. In view of the anaemia, increased polychromasia, raised bilirubin and transaminases, the patient was further evaluated. Detailed liver function tests, upper gastro intestinal (UGI) endoscopy, hepatitis viral markers, isotope study for occult gastro intestinal (GI) haemorrhage and colonoscopy did not reveal any abnormality. The cause of anaemia and bilirubinemia remained obscure. Hb electrophoresis, Coomb's test, osmotic fragility, iron studies, serum $\mathrm{B}_{12}$ and folate levels did not reveal any abnormality and PBS again showed normocytic normochromic picture with increased polychromasia. Repeat hemogram showed a gradual fall in $\mathrm{Hb}$ levels to 8.2 and $7.6 \mathrm{~g} / \mathrm{dl}$ with a rising reticulocyte count of $6 \%$ and $8 \%$ respectively. Repeat PBS done for the third time showed normocytic normochromic anaemia with basophilic stippling of the red blood corpuscles (RBCs) (Fig. 1). A decline in haemoglobin with increasing reticulocytosis and indirect hyperbilirubinemia suggested haemolysis. Basophilic stippling in the RBCs raised doubt of lead poisoning, more so as the patient was on Ayurvedic medication for psoriasis. Serum lead levels were sent for estimation which revealed a value of $115 \mu \mathrm{gm} / \mathrm{dl}$ (normal levels being $<14 \mu \mathrm{gm} / \mathrm{dl}$ ). Neurological and renal function evaluation did not reveal any abnormality. Qualitative chemical analysis of the Ayurvedic powder was done which revealed very high lead levels.

Based on above findings he was diagnosed as a case of lead poisoning leading to haemolysis and colicky abdominal pain. He was started on chelation therapy with calcium sodium

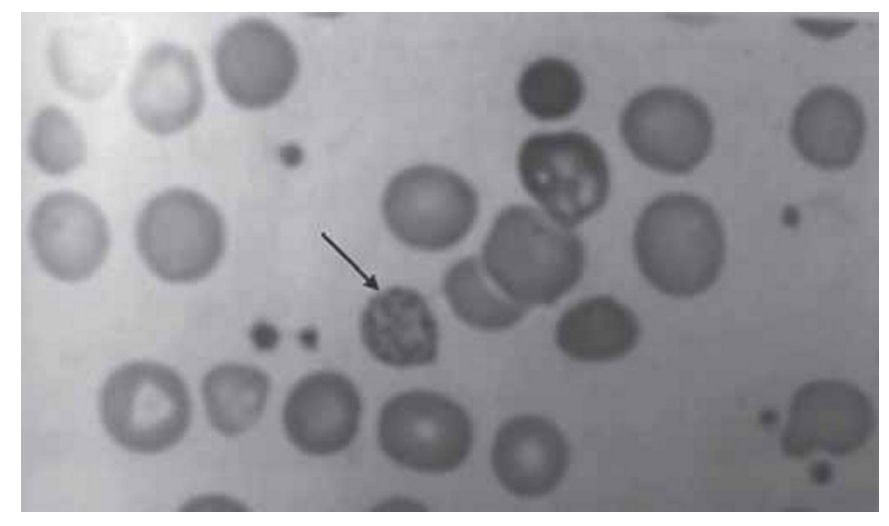

Fig. 1: PBS showing RBCs with basophilic stippling.

${ }^{*}$ Classified Specialist (Medicine \& Nuclear Medicine), ${ }^{+}$Graded Specialist (Pathology), ${ }^{* *}$ Senior Advisor (Surgery), ${ }^{++}$Senior Advisor (Medicine \& Nuclear Medicine), Command Hospital (Air Force), Bangalore 560 007. "Senior Advisor (Medicine), 7 Air Force Hospital, Kanpur \#\#Classified Specialist (Pathology \& Biochemistry), Institute of Aviation Medicine (Air Force), Bangalore. 
ethylenediamine tetra acetate (Ca Na EDTA) in the dose of $2 \mathrm{~g}\left(1500 \mathrm{mg} / \mathrm{m}^{2}\right)$ as an intravenous (IV) infusion over five days and four such courses given over three months. Over the ensuing period his serum lead levels progressively fell to $38 \mu \mathrm{g} / \mathrm{dl}$.

Patient has recovered now and is asymptomatic. He has stopped the Ayurvedic medication totally. His hemogram and liver function tests (LFT) are normal. However, his psoriatic lesions have drastically increased. He is on regular followup.

\section{Discussion}

Ayurveda is a traditional form of medicine practiced in India and other South Asian countries. Ayurvedic medications can contain herbs, minerals, heavy metals, or animal products and are made in standardized and non standardized formulations [3]. During 2000-03, a total of 12 cases of lead poisoning associated with ayurvedic medications or remedies were reported to the Centre for Disease Control and Prevention (CDC) by different states in USA [4]. Lead poisoning generally presents as an occupational hazard in populations exposed to lead. Common sources include leaded paint, lead contaminateddust and soil, airborne lead from leaded petrol and industrial emissions, water contaminated by lead pipes and food contaminated by lead soldered cans or leaded ceramics, smelting, battery making and ship building $[5,6]$. Lead poisoning has also been reported due to snooker chalk [5], from the use of cosmetics like surma [7], following ingestion of a lead foreign body [8] and due to lead gunshot pellets [9]. The presentation of lead toxicity is variable. The patients may present as acute lead poisoning which manifests as abdominal colic, constipation, fatigue, renal failure or peripheral neuropathy. In more severe cases it may present as encephalopathy especially if blood lead levels exceed $80 \mu \mathrm{g} / \mathrm{dl}$ in adults and $70 \mu \mathrm{g} / \mathrm{dl}$ in children. However, acute toxicity is uncommon [10]. Chronic lead toxicity presents as anaemia, abdominal colic, constipation, neuropsychiatric manifestations, peripheral neuropathy, deficits in short term memory and inability to concentrate. Chronic exposure may also result in interstitial nephritis, tubular damage and chronic renal failure. It may often present as acute abdomen which leads to unnecessary surgical intervention [2]. Our patient presented with pain abdomen and was planned to be taken up for cholecystectomy. Although cholelithiasis cannot be totally absolved as the cause of pain abdomen in this case, the very fact that the pain subsided on chelation therapy and has not recurred despite patient not having undergone any surgical intervention, leads us to believe that it is most likely related to lead toxicity. Our patient also had haemolysis as evidenced by anaemia, indirect hyperbilirubinemia and reticulocytosis. The elevated transaminases possibly could be part of lead toxicity or could have been drug induced, as the patient had received several antibiotics and pain killers during the four months of his symptoms prior to admission.

A normocytic normochromic blood picture with evidence of haemolysis and basophilic stippling generally points towards the diagnosis of lead poisoning [10]. In the initial stages basophilic stippling may not be evident as was in our case. Hence in case of strong clinical suspicion repeated blood smears may have to be done. Basophilic stippling was found in the third smear in our case.

The confirmatory diagnosis is however by lead estimation in blood. The normal values are less than $20 \mu \mathrm{g} / \mathrm{dl}$ for adults and less than $10 \mu \mathrm{g} / \mathrm{dl}$ in children [10]. The CDC in 1991 designated $0.48 \mu \mathrm{mol} / \mathrm{L}(10 \mu \mathrm{g} /$ dl) as the blood lead level for concern in children [11]. The adult patient with blood lead level up to $40 \mu \mathrm{g} / \mathrm{dl}$ should be observed and the source of lead should be removed. With blood lead level at 40-50 $\mu \mathrm{g} / \mathrm{dl}$, patient should be on close follow up till the blood levels are less than $40 \mu \mathrm{g} / \mathrm{dl}$. Treatment with Ca Na EDTA is indicated in symptomatic patients with blood lead levels $>50 \mu \mathrm{g} /$ dl. If blood lead levels are $>80 \mu \mathrm{g} / \mathrm{dl}$ and the patient has encephalopathy, British anti lewisite (BAL) is indicated in addition. Our patient had initial blood lead level of 115 $\mu \mathrm{g} / \mathrm{dl}$ and apart from haemolysis and abdominal colic, did not have any other manifestation of lead toxicity. Hence he was managed with EDTA to which he responded well. The blood lead level prior to discharge was $38 \mu \mathrm{g} / \mathrm{dl}$.

The case was picked up during evaluation of anaemia found during preanaesthetic (PA) check up for cholecystectomy. It highlights the importance of careful history taking, high index of suspicion, good clinical examination and involvement of multiple specialties in reaching to a conclusive diagnosis in what was thought to be a simple case of cholelithiasis and avoiding unnecessary surgical intervention. It also highlights potential risks in ayurvedic medicines as many do not pass through stringent quality control measures during preparation. There have been many case reports on the potential risks of ayurvedic medications [12,13]. In fact Kales et al [13] in their retrospective analysis of 66 cases of lead poisoning found that ayurvedic lead poisoning produced greater hematopoetic toxicity than paint poisoning.

However this case also illustrates the efficacy of ayurvedic medicines in treating conditions like psoriasis, as there was an excellent response in this patient, though at the cost of lead toxicity. If proper scientific approach and stringent quality control is undertaken with this ancient Indian system of medicine, it may prove to be 
very useful in the management of chronic diseases like psoriasis.

\section{Conflicts of Interest}

None identified

\section{References}

1. Silen W. Abdominal pain. In: Fauci AS, Joseph, MB Editors. Harrisons Principles of Internal Medicine. $17^{\text {th }}$ ed. Mcgraw Hill 2008; 91-95.

2. Mohammadi S, Mehrparvar AH, Aghilinejad M. Appendectomy due to lead poisoning: a case-report. Journal of Occupational Medicine and Toxicology 2008; $3: 23$.

3. Prpic-Majic D, Pizent A, Jurasovic J, Pongracic J, RestekSamarzija N. Lead poisoning associated with the use of ayurvedic metal-mineral tonics. J Toxicol Clin Toxicol 1996; 34: 417-23.

4. CDC. Lead Poisoning Associated with Ayurvedic MedicationsFive States, 2000-2003 MMWR 2004; 53: 582-4.

5. Dargan PI, Evans PH, House IM, Jones AL. A case of lead poisoning due to snooker chalk. Arch Dis Child 2000; 83:51920.

6. Fonte R, Agosti A, Scafa F, Candura SM. Anemia and abdominal pain due to occupational lead poisoning. Hematologica 2007; $92: 13-4$.

7. Ali AR, Smales OR, Aslam M. Surma and lead poisoning. BMJ 1978; 2: 915-6.

8. Hugelmeyer CD, Moorhead JC, Horenblas L, Bayer MJ. Fatal lead encephalopathy following foreign body ingestion: case report. J Emerg Med 1988; 6: 397-400.

9. Meggs WJ, Gerr F, Aly MH. The treatment of lead poisoning from gunshot wounds with succimer. J Toxicol Clin Toxicol 1994; 32:377-85.

10. Aggarwal P. Heavy Metal Poisoning. In: Shah SN, Paul M, editors. API Text Book of Medicine. $7^{\text {th }}$ ed. The Association of Physicians of India 2006; 1284-9.

11. CDC. Surveillance for elevated blood lead levels among childrenUnited States, 1997-2001. In: CDC Surveillance Summaries (September 12). MMWR 2003; 10: 52.

12. Schilling U, Muck R, Heidemann E. Lead poisoning after ingestion of ayurvedic drugs. Med Klin (Munich). 2004; 99: 476-80.

13. Kales SN, Christophi CA, Saper RB. Hematopoetic toxicity from lead containing Ayurvedic medications. Med Sci Monit 2007;13:295-8.

\section{Journal Scan}

Hawksworth JS, Stojadinovic A, Gage FA, Tadaki DK, Perdue PW, Forsberg J, Davis TA, Dunne JR, Denobile JW, Brown TS, Elster EA. Inflammatory biomarkers in combat wound healing. Ann Surg 2009; 250:1002-7.

Modern war ballistics and blast injuries inflict devastating extremity injuries, violating soft tissue, bone, and neurovascular structures. Despite advances in complex wound management, appropriate timing of war wound closure remains subjective. In addition, the pathophysiology of acute wound failure is poorly defined. Patients with penetrating extremity wounds sustained during combat were prospectively studied and followed for 30 days after definitive wound closure at department of regenerative medicine, Combat Casualty Care, Naval Medical Research Centre, USA. The primary outcome was wound healing. Wound dehiscence was defined as spontaneous partial or complete wound disruption after closure. Serum, wound effluent, and wound bed tissue biopsy were collected at each surgical wound debridement. Serum and wound effluent were analyzed with a multiplex array of 22 cytokines and chemokines and wound tissue for corresponding gene transcript expression. Fifty-two penetrating extremity war wounds in 33 male patients were investigated. Nine $(17 \%)$ wounds dehisced. Concomitant vascular injury, increased wound size, and higher injury severity score correlated with wound dehiscence. Both serum and wound effluent cytokine and chemokine protein profiles were statistically associated with healing outcome at various time points. Wound biopsy gene transcript expression demonstrated increased tissue inflammation associated with wound failure. Multiple protein and gene transcript biomarkers predictive of wound healing were identified. The authors concluded that the cytokine and chemokine protein and gene transcript expression patterns demonstrate a condition of inflammatory dysregulation associated with war wound failure. A molecular biomarker panel may predict combat wound healing outcome and warrants prospective validation.

\section{Contributed by}

\section{Col MM Harjai}

Senior Advisor (Surgery\& Paediatric Surgery), Command Hospital (SC) Pune-40. 